\title{
New developments in the use of prostatic stents
}

This article was published in the following Dove Press journal:

Open Access Journal of Urology

28 April 20II

Number of times this article has been viewed

\section{Athanasios G Papatsoris \\ Islam Junaid \\ Alexandra Zachou \\ Stefanos Kachrilas \\ Faruquz Zaman \\ Junaid Masood \\ Noor Buchholz}

Department of Endourology, Barts and the London NHS Trust, London, UK

Correspondence: Athanasios Papatsoris Kanari 9, I067I, Greece

$\mathrm{Tel}+302108039253$

$\mathrm{Fax}+302108044703$

Email agpapatsoris@yahoo.gr

\begin{abstract}
Bladder outflow obstruction is a very common age-related clinical entity due to a variety of benign and malignant diseases of the prostate. Surgical treatment under general or regional anesthesia is not suitable for high-risk elderly patients who seek minimally invasive management. Unfortunately, for patients who are not fit for transurethral and/or laser prostatectomy, few treatment options remain, other than long-term catheterization and insertion (under local anesthesia) of a prostatic stent. In this review, we present developments in the use of prostatic stents.
\end{abstract}

Keywords: prostatic stent, stent migration, urethal lumen, bladder outlet obstruction

\section{Introduction}

Male lower urinary tract symptoms (LUTS) due to benign prostatic hyperplasia (BPH) are common among aging men and will increase in socioeconomic and medical importance at a time of increased life expectancy. ${ }^{1}$ As many as $30 \%$ of patients with LUTS fail to achieve sufficient symptom improvement with medication, lifestyle adjustment, and fluid management and require more invasive or surgical treatment options. ${ }^{1}$ Transurethral resection of the prostate (TURP) is considered the "gold standard" surgical treatment of BPH. However, it bears a high morbidity rate (up to $20 \%$ ) with several associated risks such as bleeding, TUR syndrome, bladder neck stenosis, urethral stricture, incontinence, and impotence. ${ }^{2}$ High-risk patients may be unfit for TURP due to comorbidities such as chronic obstructive pulmonary disease, congestive heart failure, ischemic heart disease, and/or anticoagulation medication. ${ }^{2}$ For those patients, initial enthusiasm for the minimally invasive modalities of microwave thermotherapy and transurethral needle ablation has been replaced by skepticism due to the poor long-term results. Hopefully, laser prostatectomy (ie, greenlight, holmium) is a novel minimally invasive treatment of BPH that can take place without discontinuing anticoagulation medication; however, there is still a need for general or regional anesthesia. ${ }^{1}$

Unfortunately, for patients who are unfit for TURP and laser prostatectomy, few management options remain, other than long-term urethral and/or suprapubic catheterization. Catheterization negatively affects the quality of life of patients and bears the risk of urinary tract infections (UTIs) and bladder tumors, and the cost of lifelong regular catheter changes is considerable. ${ }^{3}$ Furthermore, an indwelling catheter may cause psychological distress in patients and their families. Therefore, there is a constant demand for minimally invasive techniques (ie, under local anesthesia) to treat 
bladder outlet obstruction (BOO), such as the insertion of a prostatic stent, which is the topic of this review.

Prostate stents are designed to be positioned in the prostatic urethra and the bladder neck. They should not be too close to the external sphincter, as this could cause urine incontinence. Moreover, relative contraindications to prostatic stent insertion include active UTI, gross hematuria, bladder calculi, and a large median prostatic lobe.

\section{Metal stents}

The rationale behind the use of stents in medical practice is to preserve the luminal patency of hollow structures. Metal stents were initially used in clinical practice for the management of the obstruction of coronary arteries and the biliary duct. Urologists have been far ahead of applying the concept of inserting a metal stent to keep open an obstructed conduit. The first reported use of a ureter stent dates back to the 19 th century. ${ }^{4}$

Expandable metal stents have noteworthy advantages over the spiral coil. As the expandable stent is inserted in its compressed state with the delivery system, the risk of urethral injury is lower in comparison with the spiral coil, and the implantation process is better tolerated. Moreover, the wider lumen of the metal stent once released provides a better urinary flow. Furthermore, stent migration is less frequent in comparison with the nonexpandable coil stent, because the expandable metal stent exerts a radial force on the prostatic urethra.

\section{Epithelializing/permanent stents}

These are permanent stents that promote epithelialization and become embedded in the urethra. The first one to be used in clinical practice was the Urolume Wallstent ${ }^{\circledR}$ (American Medical Systems, Minnetonka, MN), which consisted of stainless steel super alloy wire woven in a tubular mesh. The stent maintained a lumen of $42 \mathrm{Fr}$, which allowed the use of a resectoscope for future interventions. Initial studies with the Urolume Wallstent ${ }^{\circledR}$ (American Medical Systems, Minnetonka, MN) demonstrated encouraging results, as most of the patients were able to void immediately. De Vocht et al presented the long-term results of the Urolume Wallstent ${ }^{\circledR}$ after a 10-year follow-up. ${ }^{5}$ The authors inserted the Urolume Wallstent ${ }^{\circledR}$ in 15 patients and recorded two failures because of excessive tissue proliferation in the stent. In two other cases, the stent was removed due to penile pain, and two patients developed stent stenosis after 7 and 9 years. In the final evaluation, only two patients were satisfied with their stent. Masood et al reported their 12-year results of inserting the Urolume Wallstent ${ }^{\circledR}$ in 62 patients with BPH. ${ }^{6}$ Only $18 \%$ of the patients had the stent in place at the end of the follow-up period. In $40 \%$ of the cases, the stent was removed due to malpositioning, dislodgement, and irritation symptoms. Armitage et al reviewed 20 case series evaluating the Urolume Wallstent ${ }^{\circledR}$ in a total of 990 patients with BPH from 1989 to $2005 .^{7}$ Although $84 \%$ of the patients who were catheter dependent voided spontaneously, 1 of 6 men needed the Urolume Wallstent ${ }^{\circledR}$ removed within a year because of complications. Inadequate follow-up prevented conclusions on stent durability beyond 1 year. $^{7}$ Therefore, the long-term results of the Urolume Wallstent ${ }^{\circledR}$ weakened the optimistic early results. The Memotherm ${ }^{\circledR}$ (Bard, Covington, KT) stent was another permanent metal stent that could be easily inserted under local anesthesia. However, studies demonstrated a high rate of migration, recurrent UTIs, and LUTS. ${ }^{8}$

For the removal of the Urolume Wallstent ${ }^{\circledR}$, initially, the overlying urethral mucosa should be resected. Creation of a loop access space at both the proximal and distal aspects of the stent follows. Longitudinal compression with the loop further loosens the attachments of the stent to the urethra. Eventually, the stent is removed transurethrally with grasping forceps. Ease of stent removal in high-risk patients is critical because the decision to proceed with the stent placement is typically due to the presence of significant medical comorbidities that make conventional anesthesia a high-risk proposition. In case a patient requires stent removal later for whatever reason, it is unlikely that their medical condition will have improved. Thus, avoidance of general anesthesia is preferable. In contrast, nonepithelializing/temporary stents do not require second procedures for removal.

\section{Nonepithelializing/temporary stents}

The nonepithelializing expandable metal stents have noteworthy advantages over the permanent spiral coil. Although the expandable stent is inserted in its compressed state with the delivery system, the risk of urethral injury is lower in comparison with the nonexpandable spiral coil, and the implantation process is better tolerated. Moreover, the wider lumen of the metal stent once it is released provides a better urinary flow. Furthermore, stent migration is less frequent in comparison with the nonexpandable coil stent, because the expandable metal stent exerts a radial force on the prostatic urethra.

\section{First generation}

Fabian introduced the Urospiral ${ }^{\circledR}$ stent (Porges, Paris, France), which was made of coiled rust-proof stainless steel of fixed caliber and was inserted cystoscopically. ${ }^{9}$ Although early 
results were promising, explantation rates were nearly $40 \%$ because of migration and encrustation in the stent lumen. ${ }^{10}$ A similar fixed-caliber device consisting of three parts was the Prostakath $^{\circledR}$ (Engineers \& Doctors, Copenhagen, Denmark), which was gold plated for better biocompatibility. The overall success rate was $65 \%$, with no statistically significant difference between these two first-generation metal stents. ${ }^{11}$

\section{Second generation}

Newer devices were developed with more biocompatible materials such as nitinol in order to prevent encrustation. Also, they were expandable in order to prevent migration. Such a nitinol stent was the Prostacoil ${ }^{\circledR}$ stent (Instent, Eden Praire, MN), which was self-expanding and could be inserted under fluoroscopic guidance with local anesthesia. Yachia and Aridogan compared this stent with Prostakath ${ }^{\circledR}$ and concluded that the second-generation stent was more advantageous because of its larger caliber, allowing catheterization and endoscopic examinations, more flexibility, and much longer indwelling time. ${ }^{12}$

\section{Third generation}

Refinements to the second-generation stents resulted in the development of thermoexpandable stents such as the Memokath ${ }^{\circledR}$ stent (Doctors \& Engineers, Kvistjaard, Denmark), which is a nickel-titanium alloy spiral stent. ${ }^{13}$ The structure of one of these components is floppy, whereas the other is rigid, resulting in a thermosensitive "shape memory". When Memokath ${ }^{\circledR}$ stents are inserted in the correct place, they are flushed with heated water at $55-65^{\circ} \mathrm{C}$, which causes them to expand and be anchored in the desired position. With refrigerator-cold irrigation fluid, the Memokath ${ }^{\circledR}$ will soften and uncoil into a nontraumatic wire, which is easy to remove. The design of the Memokath ${ }^{\circledR}$ has advantages of ease of removal based on the properties of the alloy to assume different pliabilities and forms at different temperatures.

The Memokath ${ }^{\circledR} 028$ has been designed for the longterm treatment of patients with BOO due to BPH. ${ }^{13}$ The first generation of the Memokath ${ }^{\circledR}$ expanded along its entire length, but problems with stent migration occurred. The second generation has been available since 1992 and expands only at its distal end. It is available in lengths from $30 \mathrm{~mm}$ to $70 \mathrm{~mm}$, and its distal end expands into a cone shape $24 \mathrm{~F}$ at insertion with the most distal coils becoming $42 \mathrm{~F}$ after the instillation of hot sterile water. Armitage et al reviewed 14 case series on the use of the Memokath ${ }^{\circledR}$ in 839 men with BPH. ${ }^{14}$ The authors concluded that the Memokath ${ }^{\circledR}$ can provide an effective treatment in men at high opera- tive risk; it also seems to be safe, but inadequate follow-up does not allow firm conclusions on stent durability. In our published series of 127 patients, after a mean follow-up of 6 years, the mean International Prostate Symptoms Score decreased by 13 points and the Quality of Life Index by 3.1 points. ${ }^{15}$ Furthermore, the mean maximum flow rate increased by $7 \mathrm{~mL} / \mathrm{sec}$, and the mean residual urine volume decreased by $126 \mathrm{~mL}$.

Recently, is was demonstrated that the Memokath ${ }^{\circledR} 028$ can also be successfully inserted with a combination of transrectal ultrasonography and fluoroscopy. ${ }^{16}$ Except for cystoscopical insertion, self-expandable stents such as the Z-Stent ${ }^{\circledR}$ (Wilson-Cook Medical, Winston-Salem, NC) can be inserted under fluoroscopic guidance only. This stent is constructed of a $0.3 \mathrm{~mm}$ stainless steel wire in a cylindric, zigzag configuration of 10 bends. ${ }^{17} \mathrm{~A}$ single $\mathrm{Z}$-stent ${ }^{\mathbb{B}}$ component is $10 \mathrm{~mm}$ in diameter when fully expanded and $10 \mathrm{~mm}$ long. Three to six components are connected in tandem with metal struts and are coated with 24-karat gold for prevention of encrustation. However, relevant clinical experience with the Z-Stent ${ }^{\circledR}$ is limited.

With the aim of minimizing migration, another nitinol stent was designed with an increasing diameter toward both ends of the stent (hourglass shape) in contrast to the diameter of the Memokath ${ }^{\circledR}$, which only increased toward one end. ${ }^{18}$ Contrary to the intended design, it was demonstrated that within 2 years the majority of stents were removed due to migration. The same authors described their experience with a nitinol stent with an increasing diameter toward the distal end only (bell-shaped) with the purpose of fixing the stent at the prostatic apex. ${ }^{19}$ Clinical efficacy was demonstrated immediately; however, these results were not durable throughout the follow-up. It seems that because of the high migration rate, both the hourglass-shaped and the bell-shaped prostatic stents are not suitable for clinical practice.

\section{Fourth generation}

Prostatic urethral anatomy with the rhomboid shape at the apex and the projection of the distal posterior portion contributes to the considerable migration rates of existing stents. Marković et al developed the triangular prostatic stent, which has a large-caliber triangular cross-section to match the contours of the prostatic urethral lumen. ${ }^{20}$ This stent bears higher radial force in its main body and lower radial force in the area near the external sphincter in order to prevent sphincteric dysfunction. It conforms to the prostatic urethral lumen shape and is similar to $45 \mathrm{~F}$ of a round stent. Furthermore, the triangular prostatic stent has a special plastic 
coating in order to prevent encrustation. A small series of 23 patients with a mean follow-up of 9 months revealed good tolerability and no cases of stent migration..$^{20,21}$

\section{Nonmetal stents}

\section{Plastic stents}

Plastic prostatic stents/bridges have been designed for temporary use, such as the Spanner ${ }^{\circledR}$ stent (Abbey Moor Medical, Parkers Praire, MN). Its design is very similar to the proximal 4-6 cm of a Foley catheter; this includes a proximal balloon to prevent distal displacement, a urine port situated proximal to the balloon, and a reinforced stent of various lengths to span most of the prostatic urethra. ${ }^{22}$ The stent portion resides in the prostatic urethra, with the distal anchor residing in the bulbar urethra. Early experience with this temporary stent was encouraging, as it was easily inserted under local anesthesia and it improved the urination parameters. ${ }^{22}$ However, later experience showed that a considerable percentage of patients had an unsatisfactory outcome such as urinary retention or irritation symptoms. ${ }^{23}$

\section{Biodegradable stents}

The use of biodegradable and bioabsorbable stents has increased over the last several years. Major components of these self-expandable stents include polylactic acid, polyglycolic acid, and copolymers of lactide and glycolide. The stent properties (strength, expansion, and degradation time) can be manipulated by adjusting the type of material and stent design. The average degradation time varies from 2 months to 12 months, and stents eventually degrade to $\mathrm{CO}_{2}$ and water without needing to be removed.

Biodegradable stents are usually used in combination with 5 - $\alpha$-reductase inhibitors and intend to keep the obstructed prostatic lumen open until medication reduces the prostatic volume. The initial biodegradable prostatic stents had a spiral configuration, but they tended to migrate and collapse. To overcome these problems, scientists changed the configuration pattern and developed tubular mesh stents. A biodegradable braided poly(lactic-co-glycolic acid) (PLGA) prostatic stent has been used in combination with dutasteride for the management of acute urinary retention. ${ }^{24}$ Ten such patients were able to void after the stent insertion, and half of them continued to be able to do so after 3 months. None of the patients had any migration of the stent or incontinence due to the stent. This novel braided PLGA stent seems to overcome the earlier problems of migration and breakage into large particles. ${ }^{24}$ Nevertheless, the mechanical properties of the stent need to be improved and tested in a longer follow-up.
An interesting application of the biodegradable stent is to simulate the situation after the TURP in patients with a combination of severe $\mathrm{BOO}$ and severe overactive bladder. Several hypotheses have been proposed to explain the pathogenesis of obstructive detrusor instability, including postjunctional hypersensitivity, altered adrenoceptor function, afferent nerve dysfunction, imbalance of peptide neurotransmitters, and a myogenic defect. ${ }^{25}$ In these cases, the risk of post-TURP incontinence could be possible to assess before the operation. This so-called "stent test" indicates that patients who do not leak and who experience reduced symptoms when they are relieved of their BOO can be advised to undergo a TURP. ${ }^{25}$ Nevertheless, the "stent test" includes some possible sources of bias. In particular, the prostatic stent can cause irritation symptoms. Furthermore, the position and appropriate size of the stent are important. Also, the duration of the stent remaining in situ could be of relevant importance. The real value of the "stent test" can be assessed by a study in which all patients (with and without a stent) undergo TURP and symptoms are evaluated afterwards. ${ }^{25}$ Except for the biodegradable stents, other types of temporary stents can serve as diagnostic tools during the "stent test".

\section{Use of stents in non-BPH patients}

Prostatic stents can be used in prostate cancer patients who suffer from BOO and/or urine retention and are unfit or do not want to undergo a TURP. ${ }^{26}$ Another possible indication could be bladder neck contracture after radical prostatectomy in selected high-risk patients. Stenting is a reasonable option for severe postprostate cancer treatment stricture when patients are unwilling or unable to undergo open reconstructive surgery. Moreover, patients undergoing treatment for prostate cancer with brachytherapy might be subject to temporary BOO. ${ }^{27}$ Temporary stents have shown to offer benefits over Foley catheters in managing these patients. Recently, a study demonstrated the clinical feasibility of using a removable prostate stent as fiducial for image-guided radiotherapy of localized prostate cancer. ${ }^{28}$

Temporary stents have also been suggested as an alternative to a Foley catheter for use in patients to manage prostatic edema after undergoing minimally invasive therapy in the prostate such as transurethral needle ablation or transurethral microwave thermotherapy. ${ }^{21}$ Furthermore, prostatic stents have been advocated for use in patients awaiting surgery for a long period of time; however, little evidence exists to support this indication.

Urethral strictures can be managed with the insertion of a urethral stent, which is similar to the prostate stent. 5,20 
Usually, this is the case for bulbar urethral strictures after at least two failures of treatment with direct vision internal urethrotomy or dilatation in patients who are unfit or do not want to undergo urethroplasty. Ideally, the stricture length should be less than $3 \mathrm{~cm}$. The use of urethral stents could reduce the incidence of stricture recurrence and the need for urethral dilatations after initial treatment. In the US, most of the stents have gained approval by the US Food and Drug Administration for the specific indication of recurrent bulbar urethral strictures. ${ }^{29}$

Spinal cord injury patients who develop detrusor sphincter dyssynergia are also subject to BOO. Initial studies with a variety of stents demonstrated significant reductions in mean voiding pressure and residual urine. Recently, Rouprêt et al showed that temporary urethral stent placement may be proposed in selected patients with static BOO due to an enlarged prostate and concomitant high-risk surgical status or neurological diseases. ${ }^{30}$

\section{Conclusions}

New technologies are promising to alleviate some of the concerns regarding the use of prostatic stents, such as migration and encrustation. It is hoped that temporary biodegradable stents as well as special bioactive coatings for stents will alleviate some of the problems with current stents and render the devices more useful in clinical practice. An optimal stent would allow for initial management of BOO by maintaining patency of the urethal lumen, as well as incorporating a therapeutic agent to prevent scar recurrence, hyperplastic tissue growth, or infection. Furthermore, stents could be improved by adding radial compression stiffness and by developing stents of different sizes and lengths according to prostatic volume. Recently, Yoon et al evaluated the technical feasibility of a covered, retrievable, barbed prostatic stent and determined stent-induced histologic changes of the prostate in hormone-induced canine $\mathrm{BPH} .{ }^{31}$ The authors concluded that this stent is technically feasible and that it induced prostatic urethral dilatation. Extensive prostatic glandular atrophy persisted up to 8 weeks after stent removal.

The usefulness of prostatic stents as a remedy in cases of BPH treatment failures or as a definite therapy of $\mathrm{BPH}$ is still not clear. The European Association of Urology guidelines mention that prostatic stents are indicated in high-risk patients presenting with recurrent urinary retention as an alternative to catheterization and for those who are unfit for other types of surgery. ${ }^{32}$ High-risk patients who are unable to tolerate general or regional anesthesia can undergo prostatic stent insertion under local anesthesia. Prostatic stents need to be evaluated in scientifically robust, designed trials with cost-effectiveness data. Unfortunately, there is a lack of good-quality evidence and relevant prospective and randomized trial data. Ideally, patients should be assessed before the stent insertion with pressure flow studies to identify BOO and afterward to predict success. Although prostatic stents demonstrate some utility in the current management of BOO, large randomized controlled studies are recommended and believed to be necessary to establish their true role in this setting.

\section{Disclosure}

The authors report no conflicts of interest in this work.

\section{References}

1. Roehrborn CG. Male lower urinary tract symptoms (LUTS) and benign prostatic hyperplasia (BPH). Med Clin North Am. 2011;95(1): $87-100$.

2. Mebust WK. Transurethral prostatectomy. Urol Clin North Am. 1990; 17(3):575-585.

3. Kohler-Ockmore J, Feneley RC. Long-term catheterization of the bladder: prevalence and morbidity. Br J Urol. 1996;77(3): $347-351$.

4. Kulkarni R. Metal ureteric stents: the current situation. BJU Int. 2003; 92(3):188-189.

5. De Vocht TF, van Venrooij GE, Boon TA. Self-expanding stent insertion for urethral strictutes: a 10-year follow-up. BJU Int. 2003;91(7): 627-630.

6. Masood S, Djaladat H, Kouriefs C, et al. The 12-year outcome analysis of an endourethral wallstent for treating benign prostatic hyperplasia. BJU Int. 2004;94(9):1271-1274.

7. Armitage JN, Cathcart PJ, Rashidian A, et al. Epithelializing stent for benign prostatic hyperplasia: a systematic review of the literature. J Urol. 2007;177(5):1619-1624.

8. Uchikoba T, Horiuchi K, Satoh M, et al. Urethral stent (AngiomedMemotherm) implantation in high-risk patients with urinary retention Hinyokika Kiyo. 2005;51(4):235-239.

9. Fabian KM. The intra-prostatic "partial catheter" (urological spiral) Urologe A. 1980;9(4):236-238.

10. Tomschi W, Lüftenegger W. The urological spiral. A real alternative to the indwelling catheter? Experience in 23 patients. Wien Klin Wochenschr. 1990;102(21):650-653.

11. Braf Z, Chen J, Sofer M, Matzkin H. Intraprostatic metal stents (Prostakath and Urospiral): more than 6 years' clinical experience with 110 patients. J Endourol. 1996;10(6):555-558.

12. Yachia D, Aridogan IA. Comparison between first-generation (fixedcaliber) and second-generation (self-expanding, large caliber) temporary prostatic stents. Urol Int. 1996;57(3):165-169.

13. Staios D, Shergill I, Thwaini A, et al. The Memokath ${ }^{\mathrm{TM}}$ stent. Expert Rev Med Devices. 2007;4(2):99-101.

14. Armitage JN, Rashidian A, Cathcart PJ, et al. The thermo-expandable metal stent for managing benign prostatic hyperplasia: a systematic review. BJU Int. 2006;98(4):806-810.

15. Papatsoris AG, El-Husseiny T, Sawada Y, et al. Treating bladderoutflow obstruction with thermo-expandable prostate metal stents. Expert Rev Med Devices. 2009;6(4):357-363.

16. Minagawa T, Murata Y, Seki S. Placement of a shape-memory alloy intraurethral catheter (Memokath) using transrectal ultrasonography and fluoroscopy. Nippon Hinyokika Gakkai Zasshi. 2009;100(3): 508-512. 
17. Song HY, Cho KS, Sung KB, et al. Self-expandable metal stents in highrisk patients with benign prostatic hyperplasia: long-term follow-up. Radiology. 1995;95(3):655-660.

18. Van Dijk MM, Mochtar CA, Wijkstra H, et al. Hourglass-shaped nitinol prostatic stent in treatment of patients with lower urinary tract symptoms due to bladder outlet obstruction. Eur Urol. 2006;49(2):353-359.

19. Van Dijk MM, Mochtar CA, Wijkstra H, et al. The bell-shaped nitinol prostatic stent in the treatment of lower urinary tract symptoms: experience in 108 patients. Urology. 2005;66(4):845-849.

20. Marković BB, Marković Z, Yachia D, Hadzi DJ. A new generation of urethral stents: Allium in the therapy of symptomatic prostatic enlargement of various etiology. Acta Chir Iugosl. 2007;54(3):71-76.

21. Vanderbrink BA, Rastinehad AR, Badlani GH. Prostatic stents for the treatment of benign prostatic hyperplasia. Curr Opin Urol. 2007; 17(1):1-6.

22. Corica AP, Larson BT, Sagaz A, et al. A novel temporary prostatic stent for the relief of prostatic urethral obstruction. BJU Int. 2004;93(3): 346-348.

23. Grimsley SJ, Khan MH, Lennox E, Paterson PH. Experience with the spanner prostatic stent in patients unfit for surgery: an observational study. J Endourol. 2007;21(9):1093-1096.

24. Kotsar A, Isotalo T, Juuti H, et al. Biodegradable braided poly(lactic-coglycolic acid) urethral stent combined with dutasteride in the treatment of acute urinary retention due to benign prostatic enlargement: a pilot study. BJU Int. 2009;103(5):626-629.

25. Knutson T. Can prostate stents be used to predict the outcome of transurethral resection of the prostate in the difficult cases? Curr Opin Urol. 2004;14(1):35-39.
26. Erickson BA, McAninch JW, Eisenberg ML, et al. Management for prostate cancer treatment related posterior urethral and bladder neck stenosis with stents. J Urol. 2011;185(1):198-203.

27. Henderson A, Laing RW, Langley SE. A Spanner in the works: the use of a new temporary urethral stent to relieve bladder outflow obstruction after prostate brachytherapy. Brachytherapy. 2002;1(4):211-218.

28. Carl J, Nielsen J, Holmberg M, et al. Clinical results from first use of prostate stent as fiducial for radiotherapy of prostate cancer. Acta Oncol. December 21, 2010. [Epub ahead of print].

29. Ogiste JS, Cooper K, Kaplan SA. Are stents still a useful therapy for benign prostatic hyperplasia? Curr Opin Urol. 2003;13(1):51-57.

30. Rouprêt M, Misraï V, de Fourmestraux A, et al. Clinical relevance of urethral stents (Urospiral $2^{\mathrm{TM}}$ ) placement in patients with prostatic obstacle and concomitant high-risk surgical status or neurological diseases: a feasibility and safety study. Neurourol Urodyn. September 21, 2010. [Epub ahead of print].

31. Yoon CJ, Song HY, Kim JH, et al. Temporary placement of a covered, retrievable, barbed stent for the treatment of hormone-induced benign prostatic hyperplasia: technical feasibility and histologic changes in canine prostates. J Vasc Interv Radiol. 2010;21(9):1429-1435.

32. Madersbacher S, Alivizatos G, Nordling J, Sanz CR, Emberton M, de la Rosette JJ. EAU 2004 guidelines on assessment, therapy and follow-up of men with lower urinary tract symptoms suggestive of benign prostatic obstruction (BPH guidelins). Eur Urol. 2004;46(5):547-554.

\section{Publish your work in this journal}

The Open Access Journal of Urology is an international, peer-reviewed, open access journal publishing original research, reports, editorials, reviews and commentaries on all aspects of adult and pediatric urology in the clinic and laboratory including the following topics: Pathology, pathophysiology of urological disease; Investigation and treatment of

\section{Dovepress}

urological disease; Pharmacology of drugs used for the treatment of urological disease. The manuscript management system is completely online and includes a very quick and fair peer-review system, which is all easy to use. Visit http://www.dovepress.com/testimonials.php to read real quotes from published authors. 